\title{
Methemoglobınemia After Prilocaine: A Case Report
}

\author{
Elif Dogan Baki*, Serdar Ozkul, Ozge Okursoy, Remziye Sıvaci \\ Afyon Kocatepe University, Departmant of Anesthesiology and Reanimation,Turkey
}

*Corresponding Author: Elif Dogan Baki, Associate Prof, Afyon Kocatepe University, Faculty of Medicine, Anesthesiology and Reanimation Department, Campus of Ali Çetinkaya, Afyon-İmir Karayolu 8.km, Afyonkarahisar,03200, Turkey, Email: elifbaki1973@mynet.com.

\begin{abstract}
Aim: Methemoglobin (MetHb) is an abnormal form of the hemoglobin molecule and is at the top of the list of reasons to consider in severe central cyanosis. The most common cause of methemoglobinemia among toxins is local anesthetics used in high doses. The case is here presented of postoperative methemoglobinemia due to administration of prilocaine as a local anesthetic for scalp mass excision.

Presentation of case: A 43-year old, $70 \mathrm{~kg}$ female was scheduled for scalp mass excision by the Plastic Surgery Dept. The anaesthesia history of the patient was normal and $20 \mathrm{~mL}$ of $2 \%$ prilocaine was administered subcutaneously as local anesthetic. During the operation, which lasted approximately 55 minutes, no additional medication was administered. At 1-hour postoperatively, the saturation values of the patient fell and she was admitted to the Intensive Care Unit (ICU) for monitoring. She was tachycardic, restless, had seizure-like tremors, and her lips were mildly cyanotic. Saturation values did not increase despite the administration of 100\% oxygen. High methemoglobinemia levels (12.6\%) were determined, so 2 $\mathrm{mg} / \mathrm{kg}$ oral methylene blue was administered and improvement was seen within 2 hours.
\end{abstract}

Discussion / conclusion: The symptoms in patients with acquired methemoglobinemia are the result of an acute impairment in oxygen delivery to tissues, which does not allow sufficient time for compensatory mechanisms to function. Acute acquired methemoglobinemia should be considered in patients who have been administered local anesthetic and show signs of cyanosis.

Keywords: methemoglobinemia, prilocaine, anesthesia

\section{INTRODUCTION}

Methemoglobinemia (MetHb) occurs when the ferrous form of iron $\left(\mathrm{Fe}^{++}\right)$is converted to the ferric state $\left(\mathrm{Fe}^{+++}\right)$by oxidation in normal conditions in hemoglobin. There are two types of MetHb; congenital and acquired. The congenital type may develop due to cytochrome b5 reductase deficiency, cytochrome b5 deficiency, hemoglobin $\mathrm{M}$ disease, and patients with decreased enzymatic reduction of methemoglobinin (metHb) are mostly asymptomatic despite life-long cyanosis. The acquired type usually occurs on the withdrawal of medications (dapson, benzocaine, lidocaine, prilocaine) or agents that cause an increase in the production of methHb (2-4). However, the concentration is maintained below $1 \%$ by the intra-erythrocyte reductive system (cytochromeb5 reductase enzyme system) (2).

The case is here presented of a patient with methemoglobinemia due to local anesthetic application with prilocaine during a mass excision on the scalp.

\section{Case Presentation}

A 43-year old, $70 \mathrm{~kg}$ female was scheduled for scalp mass excision by the Plastic Surgery Dept. She had no operation with/without anesthesia before. She was monitored and $20 \mathrm{~mL}$ of $2 \%$ prilocaine was administered subcutaneously as local anesthetic. Masses of $4 \times 3$ and $2 \times 2 \mathrm{~cm}$ were totally excised. Fasciocutaneous flap was prepared laterally on the defect and advanced on the major defect. Hemostasis was achieved and the operation was terminated after appropriate closure. Removed materials were sent to pathology and reported as trichilemmal cyst. During the operation, which lasted approximately 55 minutes, no additional medication was administered except for local anesthetic. At 1-hour postoperatively, the saturation values of the patient fell and she was admitted to the Intensive Care Unit (ICU) for 
monitoring. She was tachycardic, restless, had seizure-like tremors, and her lips were mildly cyanotic. Firstly local anesthetic toxicity was considered but the dose applied was under the toxic dose. We thought that tremor may be due to hypothermia but her temperature was $36.7^{\circ} \mathrm{C}$. The vital signs were; blood pressure $=115 / 75 \mathrm{mmHg}$, heart rate $=110 /$ minute, saturation $=86 \%$. Saturation values did not increase despite the administration of $100 \%$ oxygen. Arterial blood gas values were; $\mathrm{pH}: 7.46, \quad \mathrm{pCO} 2: 25.8 \mathrm{mmHg}, \quad \mathrm{pO} 2: 95 \mathrm{mmHg}$, sat:94\%, lactate:19mg/dL, MetHb level:12.6\%. Neurology consultation was requested as the patient had seizure-like tremors, but these were not evaluated as convulsions and there were no additional suggestions. Methemoglobinemia was considered in this case because the patient had cyanosis but no history of cardiac or respiratory pathology and there had been prilocaine use with high methemoglobinemia levels. A single dose of $2 \mathrm{mg} / \mathrm{kg}$ oral methylene blue was administered to the patient and improvement was seen within 2 hours. Control blood gas values were; $\mathrm{pH}: 7.39$, pCO2:38mmHg, pO2:175mmHg, sat:99\%, lactate:3mg/dL, MetHb:1.1\%. When the physical examination findings and blood gas values were within normal normal limits, the patient was transferred to the Plastic Surgery ward.

\section{DISCUSSION}

An increase of MetHB, which is normally less than $1 \%$ of total hemoglobin $(\mathrm{Hb})$ and has no oxygen carrying capacity, can cause tissue hypoxia, lactic acidosis and death in severe cases by shifting the oxyhemoglobin dissociation curve to the left.

Methemoglobinemia should be considered first in cyanotic patients who have no evidence of circulatory or respiratory system pathologies (1). Early symptoms include palpitations, gray or blue colour change of the skin, lips and nail beds, headache, tachycardia, fatigue, dyspnea and lethargy $(4,5)$. The most common clinical symptom is peripheral cyanosis, which occurs when the level of metHb is $>1.5 \mathrm{~g}$ dL-1. Tissue hypoxia starts at $35 \%$ and at values above this, severe cyanosis occurs. When the level of MetHb reaches $>70 \%$, neurological disorders develop that can progress as far as coma and this condition is fatal (6). MetHb, which is the result of contact with oxidant substances (drug, food, chemical substance) in normal healthy individuals, is kept below $1.5-2 \%$ by the metHb reductive system (cytochrome-b5 reductase enzyme system) in erythrocytes. Methemoglobinemia occurs when the balance between oxidation and reduction is increased by oxidants, decreasing the reduction capacity, or when it is impaired by the presence of abnormal hemoglobin (7). Prilocaine is a widely used local anesthetic that can cause methemoglobinemia with a metabolite of otoluidine. The half-life of prilocaine is approximately 55 minutes and metHb may occur 20-60 minutes after ingestion (1).

Therapeutic doses of prilocaine $(1-2 \mathrm{mg} / \mathrm{kg})$ cause MetHb at levels that are generally too low to cause cyanosis, and as the dose increases, the risk of methemoglobinemia increases. However, there have been reports in literature, as in our case, of the development of methemoglobinemia after therapeutic doses (8).

Acute methemoglobinemia has been shown to occur mainly due to an increase in metHb formation due to the intake of various exogenous agents. These may occur with overdosage doses or poisonings, as well as with standard dose treatments, which can be seen especially in cases of partial deficiency of cytochrome b5 reductase. Infants and premature neonates are particularly sensitive to the formation of methemoglobinemia, as they have only $50-60 \%$ of adult red cell cytochrome b reductase activities. Therefore, the cases reported in literature have been mostly paediatricc cases, especially infants $(8,9)$. In the current case, there was no genetic screening for methemoglobin susceptibility.

Even if the $\mathrm{pO} 2$ values are normal in arterial blood gas, methemoglobinemia should be strongly considered in patients with cyanosis. The resulting hypoxia can not be corrected with an increased oxygen supply (5). In asymptomatic patients with a MetHb level lower than $20 \%$, improvement usually occurs by discontinuing the drug, and no additional drug treatment is required. If the patient is symptomatic or the level of methHb is higher than 20\%, specific treatment should be considered quickly. In treatment, methylene blue (100-200 mg oral or 1-2 mg / kg intravenous) and vitamin C (300-1000 $\mathrm{mg}$ divided doses) are given (10). Although the metHb levels $(12.6 \%)$ in the current case were not very high, methylene blue was administered as the patient had tremors resembling convulsions, cyanosis and dyspnea, and was unconscious . 


\section{CONClusion}

Acute acquired methemoglobinemia should be considered in patients who have been administered local anesthetic and show signs of cyanosis. This must be considered a medical emergency and treatment must be applied without delay.

\section{REFERENCES}

[1] Honig GR. Hemoglobin disorder. In:Behrman RE, Kleigman RM, Jenson HB, eds. Nelson Textbook of Pediatrics. Philadelpiha: Saunders, 2004:1478-88.

[2] Svecova D, Böhmer D. Congenital and acquired methemoglobinemi and its therapy. Cas Lek Cesk 1998;137(6):168-70.

[3] Agarwal N, Nagel RL, Prchal JT. Dyshemoglobinemias. In: Disorders of Hemoglobin: Genetics, Pathophysiology, and Clinical Management, 2nd ed, Steinberg M (Ed), 2009:607.

[4] Coleman MD, Coleman NA. Drug-induced methaemoglobinaemia. Treatment issues. Drug Saf 1996; 14(6):394-405.
[5] Cortazzo JA, Lichtman AD. Methemoglobinemia: a review and recommendations for management. J Cardiothorac Vasc Anesth 2014; 28:(4)1043-7.

[6] Benini D, Vivo L, Fanos V. Acquired methemoglobinemi: a case report. Pediatr Med Chir 1998;20(6):411-3.

[7] Mansouri A. Methemoglobinemia. Am J Med Sci 1985; 289(5):200-9.

[8] Kara A, Yiğit S, Aygun C, Oran O. Toxic methemoglobinemia after injection of prilocaine in a newborn case report. Turk $\mathrm{J}$ Pediatr 1998;40(4):589-92.

[9] Liao YP, Hung DZ, Yang DY. Hemolytic anemia after methylene blue therapy for aniline-induced methemoglobinemia. Vet Hum Toxicol 2002; 44(1):19-21.

[10] Pirchal J. https.www.uptodate.com.proxy. afyon.deep-knowledge.net/contents/clinicalfeatures-diagnosis-and-treatment-of methemo globinemia?source=search_result\&search=met hemoglobinemia\&selectedTitle $=1 \sim 150$ Accessed 19.02.2017.

Citation: Elif Dogan Baki, Serdar Ozkul, Ozge Okursoy, Remziye Sivaci. Methemoglobinemia After Prilocaine: A Case Report. ARC Journal of Anesthesiology. 2017; 2(2):14-16. doi: dx.doi.org/10.20431/24559792.0202005.

Copyright: () 2017 Authors. This is an open-access article distributed under the terms of the Creative Commons Attribution License, which permits unrestricted use, distribution, and reproduction in any medium, provided the original author and source are credited. 